\title{
PENINGKATAN KONDISI AREA BAHAN LABORATORIUM PRODUKSI TEKNIK MESIN FAKULTAS TEKNIK UNIVERSITAS NEGERI JAKARTA
}

\author{
Ferry Budhi Susetyo \& Rian Kurniawan Saputra \\ Jurusan Teknik Mesin Fakultas Teknik \\ Universitas Negeri Jakarta
}

\begin{abstract}
ABSTRAK
Penelitian ini bertujuan untuk meningkatkan kondisi area bahan pada Laboratorium Produksi Teknik Mesin Fakultas Teknik UNJ dengan menambah kapasitas rak bahan dan menerapkan salah satu $5 \mathrm{~S}$ pada area bahan. Penelitian ini diawali dengan pembuatan gambar kerja. Apabila gambar kerja telah dibuat maka dilakukan penambahan kapasitas rak sesuai dengan gambar kerja, dan kemudian dilakukan penataan pada area bahan berdasarkan salah satu prinsip Kaizen (dalam hal ini Seiton). Setelah dilakukan salah satu langkah $5 \mathrm{~S}$ berupa seiton atau penataan bahan-bahan praktik yang terdapat di lantai area bahan Laboratorium Produksi Teknik Mesin Fakultas Teknik UNJ dapat diletakkan di rak sehingga kondisi area bahan menjadi lebih rapi yang ditunjukkan dengan penempatan bahan praktik sesuai dengan jenisnya masing-masing.
\end{abstract}

Kata kunci: Area Bahan, Penerapan 5S

\section{A. Pendahuluan}

Pada umumnya gudang lebih dikenal sebagai sebuah tempat penyimpanan barang/stok. Warehouse atau gudang merupakan salah satu bagian dari sistem logistik dalam sebuah lembaga, di dalam warehouse kita dapat menyimpan berbagai barang, atau yang lebih akrab kita dengar dengan istilah inventory, yakni suatu tempat yang digunakan untuk menyimpan barang baik yang berupa raw material, barang work in process atau finished good.

Seperti yang kita ketahui bahwa pengadaan area bahan praktik atau gudang (warehouse) di Laboratorium Produksi Teknik Mesin Fakultas Teknik UNJ bertujuan sebagai sarana penunjang proses pembelajaran, yaitu menyimpan barang yang akan digunakan mahasiswa pada saat praktikum.

Salah satu komponen yang perlu diperhatikan dalam gudang bahan praktik Laboratorium Produksi Teknik Mesin Fakultas Teknik UNJ diantaranya adalah kondisi kapasitas rak bahan yang kurang memadai, hal ini diperkuat dengan kapasitas rak bahan tidak berbanding lurus dengan jumlah bahan yang harus disimpan dalam gudang Laboratorium Produksi Teknik Mesin Fakultas Teknik UNJ selain itu juga ditemui keterbatasan dalam proses meletakkan bahan ke rak sehingga 
membutuhkan alat bantu dalam meletakkan bahan ke rak.

Berdasarkan permasalahan diatas, penulis berniat melakukan beberapa tindakan yang dapat meningkatkan kondisi area bahan Laboratorium Produksi Teknik Mesin Fakultas Teknik UNJ berupa penerapan salah satu dari prinsip Kaizen (5S) dan penambahan kapasitas rak bahan dengan tujuan area bahan tersebut dapat dimanfaatkan secara maksimal, sehingga diharapkan proses pembelajaran di Laboratorium Produksi Teknik Mesin Fakultas Teknik UNJ dapat berjalan dengan lancar.

\section{B. Teori Dasar}

\section{a. Pengertian \\ (Inventory).}

Gudang

Inventori merupakan sebuah konsep yang mencerminkan sumber daya yang dapat digunakan tetapi tidak/belum dipergunakan.

Pengertian inventori dapat diartikan dalam beberapa hal yang berbeda, antara lain :

1) Stock yang tersedia pada saat itu juga.

2) Daftar perincian barang yang tersedia.

3) Dalam bidang keuangan dan akunting berupa jumlah persediaan barang yang dimiliki oleh suatu organisasi pada suatu waktu.

Sedangkan dalam pengertian yang lain pergudangan adalah segala upaya pengelolaan gudang yang meliputi penerimaan, penyimpanan, pemeliharaan, pendistribusian, pengendalian dan pemusnahan, serta pelaporan material dan peralatan agar kualitas dan kuantitas terjamin (Badan Nasional Penanggulangan Bencana, 2009).

\section{b. Manfaat Gudang.}

Berikut ini adalah beberapa manfaat dari sebuah gudang (inventory) yaitu:

1) Terjaganya kualitas dan kuantitas bahan.

2) Tertatanya perbekalan bahan.

3) Peningkatan pelayanan dalam proses pendistribusian.

4) Tersedianya data dan informasi yang lebih akurat, aktual, dan dapat dipertanggungjawabkan.

5) Kemudahan akses dalam pengendalian dan pengawasan.

6) Tertib secara administrasi.

\section{c. Faktor-Faktor Dalam Merancang Tata Letak Gudang.} Hal-hal yang harus diperhatikan dalam merancang tata letak sebuah gudang yaitu:

1) Untuk kemudahan bergerak, gudang jangan disekat-sekat, kecuali jika diperlukan, perhatikan posisi dinding dan pintu untuk mempermudah gerakan.

2) Berdasarkan arah arus penerimaan dan pengeluaran material dan peralatan, tata letak ruang gudang perlu memiliki lorong yang ditata berdasarkan sistem, 
a) Arah garis lurus.

b) Arah huruf U.

c) Arah huruf L.

3) Pengaturan sirkulasi udara yang cukup di dalam ruangan termasuk pengaturan kelembaban udara dan pengaturan pencahayaan.

4) Penggunaan rak dan pallet yang tepat dapat meningkatkan sirkulasi udara, perlindungan terhadap banjir, serangan hama, kelembaban dan efisiensi penanganan.

\section{d. Gudang Penyimpanan.}

Faktor yang pengaruhnya sangat besar terhadap penanganan barang ialah letak dan desain gedung di mana barang itu disimpan. Di bawah ini adalah berbagai tempat penyimpanan di mana kebutuhan yang sama dapat dipenuhi, dan dengan demikian terjadi pula proses yang sama sekali pun terdapat perbedaan dalam cara.

1) Pabrikan

a) Gudang operasional adalah gudang di mana bahan baku disimpan. Di sini dapat pula disimpan barang setengah jadi, atau suku bagian atau barang dalam proses. Barang-barang itu disiapkan untuk diserap oleh proses produksi.

b) Gudang perlengkapan, dapat berupa bengkel tambahan yang diletakkan dekat proses produksi untuk menyediakan perkakas kerja, bahan pelumas atau barang lainnya yang diperlukan oleh proses produksi, tetapi tidak ditemukan kembali di dalam produk akhir. Barangbarang itu disimpan untuk digunakan, sesudah itu dikembalikan ke gudang lagi.

c) Gudang pemberangkatan, merupakan ruang penyimpanan dari bagian pengiriman dimana barangbarang itu disimpan sebelum diberangkatkan dari pabrik. Dapat juga disebut "gudang hasil jadi".

d) Gudang musiman, dalam industri tertentu terkadang diperlukan sediaan barang yang harus disimpan dalam jumlah banyak, sehingga harus menyewa ruangan.

2) Tengkulak dan pedagang besar.

Bisnis jenis ini umumnya dibagi dalam dua kategori yaitu mereka yang membeli barang dalam jumlah besar kemudian memperkecilnya sesuai dengan tujuan dan mereka yang mengimpor atau membeli barang lokal untuk dijual lagi.

Dalam hal terakhir itu kegiatan umumnya ialah menerima dan mengalihkan barang dalam partai besar.

Para pedagang besar dalam industri tertentu menyediakan fasilitas pergudangan yang melayani sendiri (self service), yaitu pergudangan dilaksanakan, dan para pelanggan datang di tempat ini untuk memilih dan membawa sendiri barang yang diperlukan.

Pedagang eceran juga termasuk kategori ini jika mereka menyalurkan barang dari gudang 
pusat kepada cabangnya. Sebenarnya mereka memberikan pelayanan tengkulak kepada cabang-cabangnya.

1) Gudang Pengecer.

Ini berarti pembauran menyeluruh antara pedagang eceran kecil, serba ada sampai yang besar dan berantai serta perusahaan pabrikan yang terintegrasi secara vertikal.

2) Jawatan Pemerintah Pusat dan Daerah.

Instansi pemerintah dan perusahaan jawatan memiliki banyak sekali gudang untuk penjatahan barang.

3) Gudang umum dan pribadi.

Ini meliputi tempat penitipan dan penggudangan barang dan bahan milik orang lain yang bersifat hanya untuk sementara.

\section{e. Lokasi.}

Kalau kita merencanakan membangun sebuah gudang, maka harus kita telaah keadaan yang bersifat dinamis, yakni dapat bergerak dan berubah mengikuti kondisi yang yang terjadi.

Sedapat mungkin gudang itu ditempatkan dekat dengan yang membutuhkan. Ini berarti bahwa gudang pabrik harus ditempatkan dekat dekat unit produksi. Gudang penyaluran harus ditempatkan di titik yang termudah, sehingga penyaluran dapat berlangsung dengan lancar. Jika unit itu tengkulak, gudang sebaiknya ditempatkan di dekat pasar.

Seringkali gudang ditempatkan di titik yang tidak tepat, dengan alasan harga tempat itu lebih murah daripada jika ditempatkan di titik yang ideal. Akibatnya organisasi akan menderita kesulitan dan pemborosan tenaga selama bertahun-tahun, karena keputusan yang salah pada permulaannya.

Faktor-faktor penting yang harus diperhatikan sebuah lokasi gudang adalah:

1) Wilayah yang akan dilayani.

2) Daya serap dan potensi konsumen.

3) Volume masing-masing barang yang akan ditangani.

4) Metode pengangkutan.

5) Mutu jalan dan terminal.

6) Kemudahan mencapai pelabuhan, jalan kereta api, dan lapangan terbang

7) Dekatnya dengan titik tunda penyaluran.

f. Penerapan 5 S; Seiri, Seiton, Seiso, Seiketsu, Shitsuke pada Gudang.

Menurut Osada (1995), $5 \mathrm{~S}$ diartikan Seiri (pemilahan), Seiton (penataan), Seiso (pembersihan), Seiketsu (pemantapan), dan Shitsuke (pembiasaan).

1) Seiri atau pemilihan.

Hal pertama yang harus dilakuan adalah membedakan antara peralatan yang diperlukan dengan yang tidak diperlukan. Untuk membedakannya digunakan manajemen stratifikasi yang mampu membuat keputusan mengenai frekuensi pemakaian suatu peralatan yang berdasarkan tingkat kepentingan dan membuat peralatan tersebut mudah dijangkau. 
2) Seiton atau penataan.

Sebelum melakukan pelaksanaan seiton, ada persyaratan melaksanakan tahap seiton :

a) Apakah masih ada barang yang tidak dibutuhkan dalam area ?

b) Apakah semua tempat yang kotor dan bekas tempat barang yang telah dipindahkan sudah dibersihkan?

Jika persyaratan di atas telah terpenuhi, maka tahap pertama yang dilakukan dalam tahap seiton adalah dengan menyimpan peralatan di tempat yang tepat atau dalam tata letak yang benar dengan memperhatikan efisiensi dan keamanan, sehingga dapat dipergunakan dalam keadaan mendadak.

\section{3) Seiso atau pembersihan.}

Tujuan dari seiso adalah untuk menjaga kebersihan gudang dan menghilangkan debu serta kotoran yang ada di dalam gudang.

4) Seiketsu atau pemantapan.

Tahap seiketsu di gudang adalah memastikan bahwa keadaan $5 \mathrm{~S}$ dipelihara. Ini berarti melaksanakan aktivitas 5S dengan teratur sehingga keadaan tidak normal nampak, dan melatih keterampilan untuk menciptakan dan memelihara kontrol visual.

5) Shitsuke atau pembiasaan.

Pembiasaan merupakan hal yang pertama kali harus dilakukan di 5S karena melalui pembiasaan inilah pekerja dapat melakukan $5 \mathrm{~S}$ berikutnya dengan baik.

Dengan biasa melakukan maka akan menjadi habbit yang akan dilakukan secara sadar maupun tidak sadar, pembiasaan dalam konteks ini adalah biasa melakukan pemilahan, penataan, pembersihan dan pemantapan.

\section{Metode Penelitian}

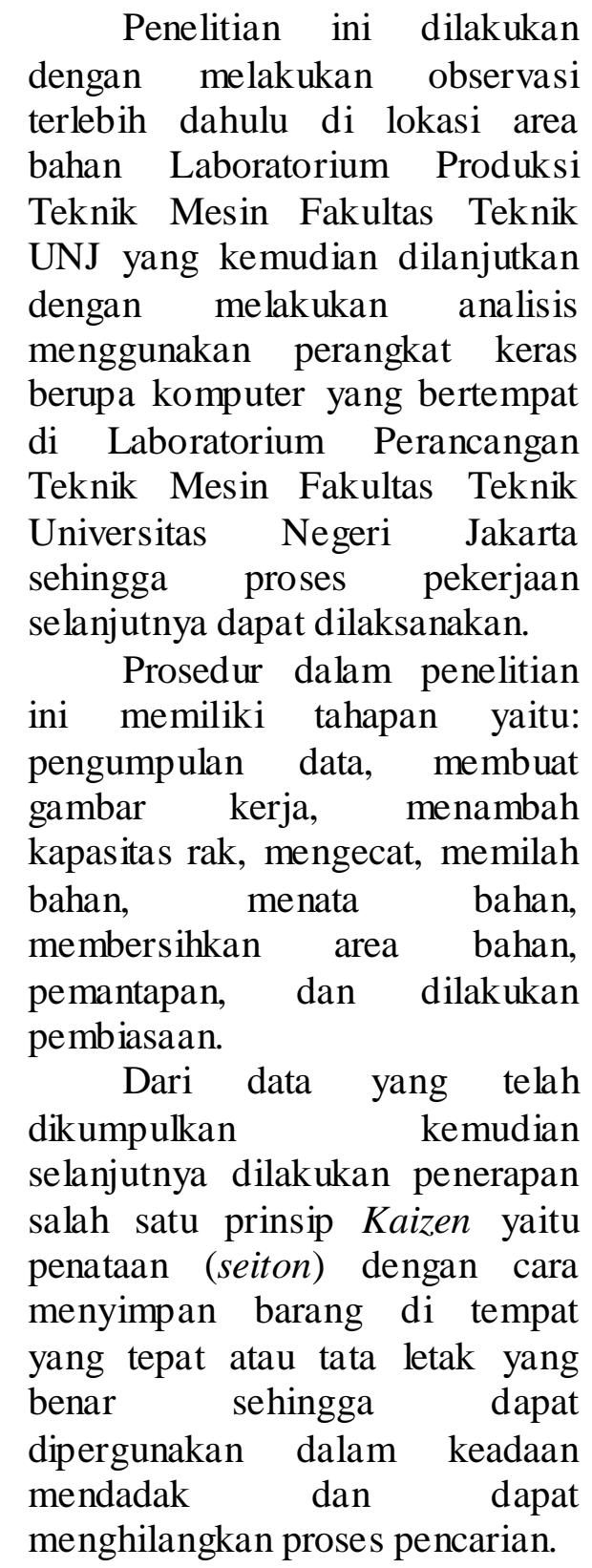
terlebih dahulu di lokasi area bahan Laboratorium Produksi Teknik Mesin Fakultas Teknik UNJ yang kemudian dilanjutkan dengan melakukan analisis menggunakan perangkat keras berupa komputer yang bertempat di Laboratorium Perancangan Teknik Mesin Fakultas Teknik Universitas Negeri Jakarta sehingga proses pekerjaan selanjutnya dapat dilaksanakan.

Prosedur dalam penelitian ini memiliki tahapan yaitu: pengumpulan data, membuat gambar kerja, menambah kapasitas rak, mengecat, memilah bahan, menata bahan, membersihkan area bahan, pemantapan, dan dilakukan pembiasaan.

dikumpulkan kemudian selanjutnya dilakukan penerapan salah satu prinsip Kaizen yaitu penataan (seiton) dengan cara menyimpan barang di tempat yang tepat atau tata letak yang benar sehingga dapat dipergunakan dalam keadaan mendadak dan dapat 


\section{Hasil Penelitian}

Seiton (penataan) dirancangkan dengan menata bahan yang terdapat di area bahan Laboratorium Produksi Teknik Mesin Fakultas Teknik UNJ agar dekat dengan aktivitas yang akan dilakukan pada saat proses kegiatan belajar sehingga mempunyai efisiensi waktu dari penundaan kerja.

Sebelum

melakukan pelaksanaan seiton, ada persyaratan dalam melaksanakan tahap seiton:

1. Apakah masih ada barang yang tidak dibutuhkan dalam area?

2. Apakah semua tempat yang kotor dan bekas tempat barang yang telah dipindahkan telah dibersihkan?

Jika persyaratan di atas telah terpenuhi semua, selanjutnya dilakukan prosedur dasar dalam proses penataan area bahan Laboratorium Produksi Teknik Mesin Fakultas Teknik UNJ yaitu :

1. Memahami kondisi mengenai bagaimana orang yang ada di area bahan mengambil dan menyimpan bahan, serta berapa waktu yang diperlukan dalam melakukan kegiatan tersebut.

2. Menentukan di mana barang yang akan disimpan.

a. Membuang bahan yang sudah tidak diperlukan. Hal ini dilakukan setelah berkonsultasi terlebih dahulu dengan pihak pengelola area bahan
Laboratorium Produksi

Teknik Mesin Fakultas

Teknik UNJ.

b. Mengelompokkan bahan sesuai dengan jenisnya. Yaitu menentukan bahan plat, besi cor, dan yang lain untuk disimpan di rak bahan.

3. Menentukan bagaimana menyimpan barang.

a. Meletakkan bahan pada rak sesuai dengan jenis yang telah ditentukan sebelumnya hal ini dilakukan agar mempermudah pengelola dalam mencari bahan yang diperlukan.

b. Membuat standar pemberian nama pada tiap kolom rak untuk mempermudah

penyimpanan dan pencarian bahan.

4. Taati aturannya.

a. Melakukan pencatatan inventaris bahan yang terdapat di area bahan Laboratorium Produksi Teknik Mesin Fakultas Teknik UNJ sehingga dapat diketahui jumlah bahan yang dimiliki.

b. Pembuatan instruksi kerja sebagai pedoman peletakkan dan pengambilan bahan. 
Berikut ini adalah kondisi Area

Bahan Laboratorium Produksi

Teknik Mesin Fakultas Teknik UNJ

sebelum dan sesudah dilakukan penataan.
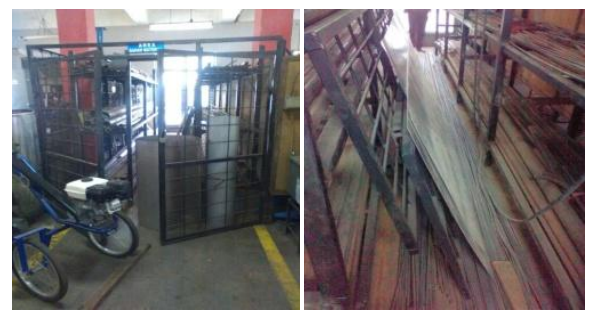

Gambar Sebelum dilakukan penataan.

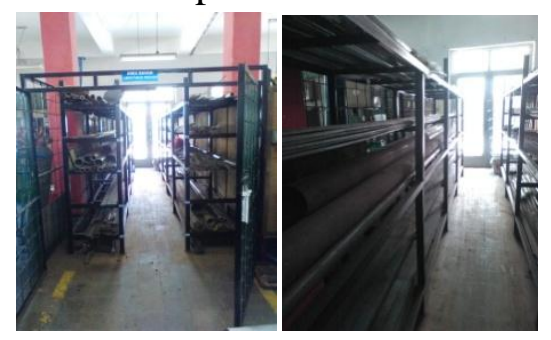

Gambar Setelah dilakukan penataan.

\section{E. Penutup}

Setelah dilakukan penataan, area bahan Laboratorium Produksi Teknik Mesin Fakultas Teknik UNJ menjadi lebih rapi. Hal ini dapat dilihat dari bahan yang berada di lantai dapat diletakkan pada rak sesuai dengan katagori yang telah dilakukan ditentukan. Selain itu jumlah kolom pada rak juga meningkat yang awalnya terdiri dari tiga kolom menjadi lima kolom sehingga kapasitasnya meningkat dalam menyimpan bahan.

Setelah melakukan penelitian ini, untuk penelitian selanjutnya peneliti memberikan saran bahwa pembuatan rancangan ini juga perlu memperhitungkan faktor ekonomis, oleh karena itu, sebaiknya pada penelitian berikutnya juga menghitung biaya produksi mencakup harga material serta biaya pembuatan. Selanjutnya perlu dibuat alat bantu yang memudahkan dalam proses meletakkan bahan di rak sehingga dapat menghemat waktu dan tenaga selama meletakkan bahan di rak. Diharapkan penerapan $5 \mathrm{~S}$ pada area bahan Laboratorium Produksi Teknik Mesin Fakultas Teknik UNJ dapat dilakukan dengan sepenuhnya dan berkesinambungan sehingga kondisi area bahan dapat terus ditingkatkan menjadi lebih baik dari sebelumnya.

\section{F. Daftar Pustaka}

Abdat, Djamal Muhammad, Modul Struktur Baja II, (Jakarta : Pusat Pengembangan Bahan Ajar Universitas Mercu Buana, 2011)

Akin, J.E., FEA Concepts: SW Simulation Overview, (World Scientific, 2009)

Dahlan, Dahmir, Elemen Mesin, (Jakarta: Citra Harta Prima, 2012)

Graha Bangun Jaya, Konstruksi Baja Bangunan Pabrik, Gudang, Workshop [terhubung berkala] http://grahabangunjaya.com/kon struksi-baja-bangunan-pabrikgudang-workshop/diakses pada tanggal 2 Maret 2015 pada pukul 11.23.

H.W iryosumarto dan T. Okumura, Teknologi Pengelasan Logam, 
(Jakarta : PT. Pradnya Paramita, 1994)

Jensen/Chenoweth, Kekuatan Bahan

Terapan, (Jakarta:Erlangga, 1989)

Peraturan Kepala Badan Nasional

Penganggulangan bencana

Nomor 6 Tahun 2009

Prufwesan, Glasso, terjemahan Nur

Amansyah, Pengecatan, (Bogor

: Mercedes Benz, 1984)

Rahman, Faisal dan Tony Hartono

Bagio, Sistem Inventory dengan

Menggunakaan Metode First In

First Out (FIFO), (Surabaya :

Universitas Narotama, 2008)

Sukrisno, Umar, Bagian-Bagian

Mesin dan Merencana, (Jakarta

: Erlangga, 1984)

Sumarto, Harsono Wiryo dan Toshie

Okumura, Teknologi Pengelasan

Logam, (Jakarta :PT Pradya

Paramitha, 1979)

Sunaryo, Hery, Teknik Pengelasan

Kapal, (Jakarta : Direktorat

Pembinaan Sekolah Menengah

Kejuruan Departemen

Pendidikan Dasar dan

Menengah, 2008)
Syarippudin, Diktat Mata Kuliah Teknik Pengelasan, (Jakarta : FT UNJ, 2004)

Toyota Astra Motor, Painting Training Manual: Pedoman Pelatihan Pengecatan, (Jakarta : PT. Toyota Astra Motor, 1995)

Toyota Astra Motor, Painting Training Manual: Step 2, (Jakarta : PT. Toyota Astra Motor, 1995)

Tun Ariyul Fikri (et.al.), Analisis Sistem Administrasi Pergudangan Dinas Kesehatan Kabupaten Kepulauan Meranti Jurnal Kesehatan Politeknik Negeri Bengkalis, (Pekanbaru : Politeknik Negeri Bengkalis ,2013)

Warman, John, Manajemen Pergudangan, (Jakarta : Pustaka Sinar Harapan, 1995)

Wisesa, Purba, Rancangan $5 S$ Pada Gudang Minyak Goreng Distributor PT. Gading Purik Perkasa; Jurnal Ilmiah Mahasiswa Universitas Surabaya, Vol. 2 No. 2, (Surabaya : Universitas Surabaya, 2013) 